\title{
Irving Fisher and the UIP Puzzle: Meeting the Expectations a Century Later
}

\author{
Rachel A. Campbell, Kees G. Koedijk, James R. Lothian \\ and Ronald J. Mahieu
}

\begin{tabular}{|l|l|}
\hline \multicolumn{2}{|l|}{ ERIM REPORT SERIES RESEARCH IN MANAGEMENT } \\
\hline ERIM Report Series reference number & ERS-2007-088-F\&A \\
\hline Publication & December 2007 \\
\hline Number of pages & 44 \\
\hline Persistent paper URL & http://hdl.handle.net/1765/10774 \\
\hline Email address corresponding author & rmahieu@rsm.nl \\
\hline Address & Erasmus Research Institute of Management (ERIM) \\
& RSM Erasmus University / Erasmus School of Economics \\
& Erasmus Universiteit Rotterdam \\
& P.O.Box 1738 \\
& 3000 DR Rotterdam, The Netherlands \\
& Phone: + 31 104081182 \\
& Fax: + 31104089640 \\
& Email: info@erim.eur.nl \\
& Internet: www.erim.eur.nl \\
\hline
\end{tabular}

Bibliographic data and classifications of all the ERIM reports are also available on the ERIM website: www.erim.eur.nl 


\section{ERASMUS RESEARCH INSTITUTE OF MANAGEMENT}

\section{REPORT SERIES}

\section{RESEARCH IN MANAGEMENT}

\begin{tabular}{|l|l|}
\hline \multicolumn{2}{|l|}{ ABSTRACT AND KEYWORDS } \\
\hline Abstract & $\begin{array}{l}\text { We review Irving Fisher's seminal work on UIP and on the closely related equation linking } \\
\text { interest rates and inflation. Like Fisher, we find that the failures of UIP are connected to } \\
\text { individual episodes in which errors surrounding exchange rate expectations are persistent, but } \\
\text { eventually transitory. We find considerable commonality in deviations from UIP and PPP, } \\
\text { suggesting that both of these deviations are driven by a common factor. Using a dynamic latent } \\
\text { factor model, we find that deviations from UIP are almost entirely due to expectational errors in } \\
\text { exchange rates, rather than attributable to the risk premium; a result consistent with those } \\
\text { reported by Fisher a century ago. }\end{array}$ \\
\hline Free Keywords & Irving Fisher, UIP, PPP, inflation, interest rates, exchange rates \\
\hline Availability & $\begin{array}{l}\text { The ERIM Report Series is distributed through the following platforms: } \\
\text { Academic Repository at Erasmus University (DEAR), DEAR ERIM Series Portal } \\
\text { Social Science Research Network (SSRN), SSRN ERIM Series Webpage } \\
\text { Research Papers in Economics (REPEC), REPEC ERIM Series Webpage }\end{array}$ \\
\hline Classifications & $\begin{array}{l}\text { The electronic versions of the papers in the ERIM report Series contain bibliographic metadata } \\
\text { by the following classification systems: } \\
\text { Library of Congress Classification, (LCC) } \underline{\text { LCC Webpage }} \\
\text { Journal of Economic Literature, (JEL), JEL Webpage } \\
\text { ACM Computing Classification System CCS Webpage } \\
\text { Inspec Classification scheme (ICS), ICS Webpage }\end{array}$ \\
\hline
\end{tabular}




\section{Irving Fisher and the UIP Puzzle:}

\section{Meeting the expectations a century later}

We review Irving Fisher's seminal work on UIP and on the closely related equation linking interest rates and inflation. Like Fisher, we find that the failures of UIP are connected to individual episodes in which errors surrounding exchange rate expectations are persistent, but eventually transitory. We find considerable commonality in deviations from UIP and PPP, suggesting that both of these deviations are driven by a common factor. Using a dynamic latent factor model, we find that deviations from UIP are almost entirely due to expectational errors in exchange rates, rather than attributable to the risk premium; a result consistent with those reported by Fisher a century ago. (JEL F31, B1) 


\title{
Irving Fisher and the UIP Puzzle: Meeting the expectations a century later
}

August 2007

\author{
Rachel A. Campbell, \\ Maastricht University and RSM Erasmus University \\ Faculty of Economics and Business Administration, Maastricht University, P.O. Box \\ 616, 6200 MD Maastricht, The Netherlands, tel. 3143 388-4827, e-mail: \\ r.campbell@,finance.unimaas.nl.
}

\begin{abstract}
Kees G. Koedijk
RSM Erasmus University and CEPR

Department of Financial Management, RSM Erasmus University, Room T9-59, Burgemeester Oudlaan 50, P.O. Box 1738, 3000 DR Rotterdam , The Netherlands, tel. 31 104082 748, e-mail: ckoedijk@,rsm.nl.
\end{abstract}

\section{James R. Lothian \\ Fordham University}

Graduate School of Business, Fordham University, 113 West $60^{\text {th }}$ Street, New York, NY 10023, USA, tel., 1212 636-6147, e-mail: lothian@,fordham.edu ; jrmlothian@aol.com .

\section{Ronald J. Mahieu}

RSM Erasmus University and Netspar

Department of Financial Management, RSM Erasmus University, Room T9-59, Burgemeester Oudlaan 50, P.O. Box 1738, 3000 DR Rotterdam , The Netherlands, tel. 31 104082 295, e-mail: rmahieu@,rsm.nl. 
Of the three major international parity relations, uncovered interest rate parity (UIP) has proven to be the most troublesome empirically. According to UIP, the difference between interest rates in two different currencies will equal the rate of change of the exchange rate between those currencies. However, most studies fail to find this positive one-to-one relation and, indeed, many find a negative relation. ${ }^{1}$

To Irving Fisher, who arguably was the first economist to formulate the UIP condition, these anomalous results probably would not have come as much of a surprise (Dimand, 1999). Fisher viewed UIP as the international dual of the within-country relation between interest rates and inflation relation that has come to be known as "the Fisher Equation." ${ }^{2}$ He saw them as two facets of a general relation linking interest rates in different standards, in his terminology, the relation between "appreciation and interest."

Fisher discussed this relation first in a monograph of that title published in 1896 by the American Economic Association, and subsequently in two books on the subject of interest-rate determination, the Rate of Interest (1907) and his later and more often cited Theory of Interest (1930).

In the Fisher equation, the interest rates in question are the nominal and real rates of interest and the link between them, the expected rate of inflation, i.e., the rate at which money is expected to depreciate (or appreciate) in terms of goods. For UIP, the interest rates are the nominal interest rates of the two countries in question and the link between

\footnotetext{
${ }^{1}$ See, for instance, Backus, et al (2001), Bekaert and Hodrick (2001), Bekaert, et al. (2003), Brennan and Xia (2005), Chinn (2006), Engel (1996), Fama (1984), Flood and Rose (2002), Hodrick (1987), Lothian and $\mathrm{Wu}(2005)$.
} 
them the expected rate of change of the exchange rate, the rate at which the one currency is expected to depreciate (or appreciate) in terms of the other.

In Fisher's discussions of the empirical evidence surrounding the relation between interest and inflation, he saw it as very often subject to violation in the real world. The reason, he claimed, was that people generally did not "adjust at all accurately and promptly" to changes in the behavior of prices but did so only with a long lag (1930). For UIP, he made much the same argument, presenting evidence of incomplete and delayed adjustment of nominal interest rate differentials to exchange rate movements and also of episodes which now fall under the heading of "peso problems" in which agents anticipate changes that have not yet occurred.

In this paper, we first briefly review Fisher's work on this subject. When we reexamine the performance of UIP since the advent of floating exchange rates in the 1970s, we find the evidence is consistent with Fisher's conjectures. Like Fisher, we find that the failures of UIP are related to individual episodes in which exchange rate expectation errors have been persistent, but which eventually are transitory. The first piece of evidence that supports this inference is the improvement in performance of the UIP that we find as we average the data over progressively longer periods. Errors made in forecasting the exchange rate are much less important in the long run, and the larger sample improves estimation so that the parity condition is more stable. Our second piece of evidence comes from analysis of UIP in conjunction with the other two key international parity conditions, purchasing power parity (PPP) and real interest rate equality (RIE). The short-term deviations away from UIP and PPP are both substantial and highly correlated. This empirical evidence again points to exchange rate forecast 
errors, as opposed to the risk premium, as the major force driving the UIP deviations. We see substantial evidence of this in another way when we examine the deviations away from RIE, which in principle are independent of exchange rate forecast errors. These deviations are relatively small in comparison to the deviations away from the other two parity conditions, and are less correlated with them.

A third piece of evidence derives from a dynamic latent factor model that we use to estimate the magnitudes of the effects of the risk premia and exchange rate forecast errors on the UIP relation. For all of the currencies for which we estimate this model, exchange rate forecast errors again appear to be the principal force behind deviations from UIP. Our results provide support to the evidence found from survey data in Froot and Frankel (1989).

Moreover, these results are robust to alternative model specifications and across countries and time periods. Our results confirm that deviations from UIP are due to forecast errors, made in anticipation of expected changes in the future exchange rate rather than attributable to the risk premium. This is a result which is often claimed as due to irrational behavior of investors, and the failure of rational expectations. However, the result can be consistent with investor rationality when changes occur in the process governing the exchange rate. For example a shift in monetary policy, learning behavior, or what is now commonly termed 'peso problems' will mean that investors could not expect to foresee errors in the sample period, although these errors would appear to be systematic ex post.

Fisher's claim, made in 1907, that "unforeseen monetary changes" are the major cause of departures from UIP and the appreciation-interest relation more generally appear 
confirmed (1907, p. 279). We, therefore, attribute the argument that expectational errors rather than the risk premia are the major cause of UIP failure to the observations made by Irving Fisher a century ago.

The paper is organized as follows. In section I we review Fisher's work on UIP. In Section II we provide empirical results on the short and long run behavior of UIP. In Section III we analyze the sources of deviations away from UIP. In Section IV we show that it is predominately expectational errors which account for the deviations away from UIP in the short run. Section V concludes.

\section{Fisher on UIP and the relation between appreciation and interest}

Fisher's investigation of UIP centered on two bodies of data: yields on long-term U.S. bonds over the period 1870 to 1896 , one bond payable in gold and the other in paper, or "greenback," currency; and yields on long-term Indian bonds traded in London between 1865 and 1894, one bond payable in sterling and the other in silver rupees. Fisher discusses these results first in his monograph Appreciation and Interest (1896), and then in his two books on the subject $(1907,1930)$.

In his analysis of the U.S. data, Fisher discusses two important episodes, the 1879 resumption of specie payments and the decades surrounding that episode, and the 1896 presidential election and three years preceding it. In both events he found evidence of behavior consistent with theory. Prior to resumption, yields on currency bonds exceeded yields on gold bonds as they should have, given the expectations of an appreciation in the value of the paper currency relative to gold. At its peak in 1870, the spread between the two stood at 100 basis points. As time passed and the U.S. price level expressed in terms 
of the paper currency converged to the price level expressed in terms of gold, the spread narrowed, and by mid- 1878 had reversed sign. Over the next 15 years the spread between the yields on currency and gold bonds averaged only -37 basis points, and in the earlier part of that period generally stood at -20 basis points or less.

Fisher went on to compare the expected rates of appreciation of the greenback implicit in the yield differentials prior to resumption. In his comparisons he used realized rates over progressively shorter periods, beginning in January 1870 and ending in each instance in January 1879 , the actual date of resumption. The expected rate at the start of this sample was 0.8 percent per annum compared to a realized rate of 2.1 percent per annum, a ratio of a bit less than two fifths. Such underestimation was not at all unusual. Not until 1877 did the ratio finally break out of that general range. For a time in 1874 it actually went negative, implying expectations of depreciation rather than appreciation.

If adjustment was incomplete for most of the period prior to resumption, it was certainly not the case in the years leading up to the 1896 presidential election. During that episode, the first of the two peso-problems uncovered by Fisher, which we noted above, developed. Yields on currency bonds and gold bonds both increased, and the spread between the two progressively widened from 30 basis points in 1893 to a peak of 110 basis points in 1896. Fisher's explanation, which subsequent research substantiates, attributed these developments to the free-silver agitation and the fears of impending inflation and dollar depreciation that it engendered. ${ }^{3}$ "Both the increases and the wedging apart of the two rates are explainable as effects of the free-silver proposal and its

\footnotetext{
${ }^{3}$ Hallwood, et al. (2000) provide econometric evidence supporting this interpretation. For historical discussions of this episode see Friedman and Schwartz (1963, Chapter 3; 1982, Chapter 7).
} 
incorporation (July 1896) in the platform of the democratic [sic] party," Fisher wrote (1930).

Fisher conducted a similar analysis using the yield data for India. In the period 1865-1874 when the exchange rate was stable, the yields on gold and silver rupee bonds were almost identical, differing on average by roughly 20 basis points. Then, in 1875 , as the rupee began to depreciate, the spreads gradually widened, from an average of close to 40 basis points in the period between 1875 and 1878 , to 64 basis points during the period 1879-1887, to over 100 basis points from 1888 through the first half of 1890 . After further depreciation in the half decade that followed, the exchange rate stabilized at the par value of $16 \mathrm{~d} /$ rupee.

Fisher pointed out that market reactions, both to the initial decline and to the eventual stabilization of the rupee, although basically in line with theory, came with substantial lags. In the latter instance, market participants apparently anticipated a further depreciation in the exchange rate, but this depreciation never actually materialized. This incident is the second of the two peso problems highlighted by Fisher.

In the Theory of Interest (p. 407), regarding this incident Fisher wrote:

"[T]he legal par was reached in 1898 and was maintained thereafter, subject only to the slight variations of exchange due to the cost of shipping specie. But until the par was proved actually stable by two or three years' experience, the public refused to have confidence that gold and the rupee were once more to run parallel. Their lack of confidence was shown in the difference in the rates of interest in gold and rupee securities during the transition period, 1893-1898, and the two or three succeeding years." (Emphasis is ours)

The rest of Fisher's empirical evidence concerned the behavior of nominal interest rates within countries, in particular Britain and the United States, but also France, Germany, India, Japan, and in the Rate of Interest, but not the Theory of Interest, China. 
This evidence ranged from brief historical descriptions of important episodes, to comparisons of the direction of change in nominal interest rates and rates of price change between subperiods of varying lengths, chosen according to whether prices were rising or declining, to comparisons of the standard deviations of nominal interest rates and ex post real interest rates derived from the subperiod data, and later, in The Theory of Interest, to his computation of simple correlations between contemporaneous values of nominal interest rates and inflation rates and the estimation of distributed lag relations between those two variables.

The standard deviations of ex post real interest rates were many multiples of the standard deviations of the nominal interest rates in every instance, ratios four to eight times greater in the data analyzed in The Rate of Interest and seven to 13 times greater in the data analyzed in The Theory of Interest.

Fisher's comparisons of the changes in inflation rates and ex post real interest rates in The Rate of Interest tell a similar story. Increases in inflation went hand in glove with decreases in ex post real rates, again implying much less than complete adjustment in nominal rates.

Fisher's summation of this evidence is highly illuminating (1907, p. 278):

There are two possible explanations for [this inverse relation]. ... One is that when prices are rising the cause may not be monetary but may lie in a progressive scarcity of commodities produced and exchanged ... The second reason is that these [price] movements are only imperfectly foreseen"

He went on to argue (1907, p 279):

Doubtless both of these causes play a part in the explanation in particular cases. Nevertheless there is internal evidence to show that in general the latter factorunforeseen monetary changes - is the more important. This evidence consists in the fact that commodity interest fluctuates so widely in some instances becoming negative. (Emphasis is ours) 
However, he concluded (1907, p. 282) that "When long periods of price movements are taken, the influence of appreciation on interest is more certain ... because [i]n averages covering so many years we may be sure that accidental causes are almost wholly eliminated." Fisher's discussion here, though terse and rather offhand, is very much in line with the later treatments of Friedman and Schwartz (1991) and Lucas (1980), on the importance of accounting for errors in variables, defined as Friedman and Schwartz put it to include "all stochastic disturbances affecting the variables under study" and of filtering to capture fundamental long-run relations. As in much else, Fisher was again ahead of his time.

Fisher went on to present evidence for Britain and the United States using averages spanning a decade or more that was entirely consistent with his statement (1907). The direction of the movements in nominal interest rates and inflation in seven of the eight cases is the same and the variability of the ex post real rates is much closer to that of the nominal rates in both countries than in the data for the shorter subperiods.

\section{UIP regressions}

Following Fischer's premise, substantial evidence abounds that UIP does not in fact hold, or at least not in the short term. Engel (1996) provides a comprehensive survey of this literature. However, is this failure of UIP to hold a consequence of a time varying risk premium, or to systematic expectational errors in forecasting exchange rates? We begin by showing that empirically UIP does not hold in the short run.

We use monthly data for the period January 1976 to December 2005 for 20 countries relative to the United States: Australia, Austria, Belgium, Canada, Denmark, 
Finland, France, Germany, Greece, Ireland, Italy, Japan, Netherlands, New-Zealand, Norway, Portugal, Spain, Sweden, Switzerland, and the United Kingdom. We obtain most of these data from the International Monetary Fund's International Financial Statistics. Exchange rates are denominated in units of foreign currency per U.S. dollar; interest rates are short-term domestic Treasury bill or money market rates.

\section{II.A. UIP Regressions}

We begin by running standard UIP regressions of the following form in Equation (1) for each country individually over the full sample period:

$$
s_{t+1}-s_{t}=\alpha+\beta\left(i_{t}-i_{t} *\right)+e_{t+1},
$$

where $s_{t+1}-s_{t}$ is the one-period change in the log spot exchange rate, measured as the foreign currency price of the U.S. dollar, and $i_{t}-i_{t} *$ is the foreign interest rate differential, measured as the foreign minus the U.S. interest rate.

Under the UIP hypothesis, if the return on a domestic one-period zero coupon bond is one percentage point per annum higher than that on a foreign bond, we would expect that on average, the foreign currency would appreciate by one percent over the next period. Therefore, a test of the hypothesis $\alpha=0$ and $\beta=1$ in (1) provides a test of uncovered interest parity.

However, most studies reject this hypothesis. Indeed, one of the most puzzling features of exchange rate behavior since the advent of floating exchange rates in the early 1970s is the tendency for countries with high interest rates to see their currencies 
appreciate rather than depreciate, as UIP would suggest. This UIP puzzle, also known as "the forward premium puzzle," is now so well-documented that it has taken on the aura of a stylized fact. As a result it has spawned an extensive second-generation body of literature that attempts to explain it.

\section{Insert Table 1}

The regression results we report in Table 1 are very much in line with results reported in other studies. In 15 of the 20 countries, the estimates of $\beta$ are significantly different from the theoretical value of unity at the five per cent level or below. In all instances the coefficients of determination in these regressions are extremely low, and in most instances close to zero. There is little if any evidence that UIP holds in the monthly data for these countries. ${ }^{4}$

To add an additional perspective with which to view both these results and Fisher's earlier analysis, we ran similar regressions using Irving Fisher's original data for the United States and India. We obtained these data from Tables 11 and 12 in Chapter 19 of The Theory of Interest (1930). Our results are reported in Table 2 and are similar to those reported in Table 1. In the U.S. case, the estimate of the slope coefficient $\beta$ is positive, and in the Indian case, negative. In both cases, these estimates are both insignificantly different from zero and insignificantly different from unity and the regressions explain relatively little of the variation in exchange-rate changes. So, while Fisher - quite legitimately we believe - was able to point to subperiods in which UIP had

\footnotetext{
${ }^{4}$ The low explanatory of UIP regressions is a stylized fact that has gone largely unnoticed in the literature. See Lothian and $\mathrm{Wu}(2005)$ for a discussion of this issue.
} 
some validity, the relation does not pass econometric muster over his two full sample periods.

\section{Insert Table 2}

Fisher's explanation for the failures of UIP and the appreciation-interest relation center more generally, as we have already discussed, centered on small-sample problems and Fisher's other "accidental" factors affecting that relation. To investigate the possible effects of such influences on our data, we ran rolling regressions and regressions using pooled data averaged over progressively longer time periods.

\section{B. Rolling regressions}

In Figure 1, the solid line plots cross-country averages of the slope coefficients of five-year rolling regressions based on equation (2) and estimated for the G7 countries to show that there was a high degree of co-movement in these regressions over the subset of countries. The averages are for the period 1976:1 and 2005:12.

We plot the coefficients from 5 year rolling regressions for the data sample at the starting points of the sample periods over which the regressions are run in Figure 1. What stands out in the figure are the often sizable variations in the slope coefficients over time. We see periods, such as the early 1990s, during which most of the individual-country coefficients are positive and for a time close to unity. But we also see these periods followed by long periods of systematic movements away from this UIP value.

\section{Insert Figure 1}


The first such departure occurred at the beginning of the sample in the 1980s. At the start of the decade, we see a gradual decrease in the magnitude of the regression slope coefficients and then large negative values by the middle of the decade. This decade was the period of Reagan-Volcker disinflation, when the Federal Reserve contained and then reversed the process of rising inflation. However, expectations for the inflation decline changed more slowly. During the following five year period, we see a gradual reversion towards unit slope coefficients in the rolling UIP regressions and hence a return to UIP.

A second major shock was the 1992 ERM crisis, when the United Kingdom, followed later by Italy and Spain, pulled out of the European Monetary System. Here we see a sharp rise in the average slope coefficient.

A third major event, like the one in the 1980s in which we see falling and eventually negative slope estimates, began in the mid to late 1990s prior to the introduction of the euro. This event appears attributable to the uncertainty that accompanied that episode.

\section{II.C. UIP regressions using temporally averaged data}

If the current problems surrounding UIP are in fact episodic phenomena that are due, as Fisher put it (1907, p. 282), to "accidental causes," then his solution of averaging the data are a way of mitigating these problems.

We do this averaging in Figure 2 and in the regressions in Table 3. In the three panels of Figure 2 we show the plots of the UIP relation based on five-year, fifteen-year, and full-period averages of the data for our 20 countries. To provide a theoretical frame 
of reference, we also show a 45 degree line drawn through the origin. In Table 3 we list the corresponding regression results.

\section{Insert Figure 2 \& Table 3}

In the five-year averaged data there is a positive, but nevertheless weak, relation between the exchange rate change and the interest differential. However, the picture changes markedly as the period over which we average the data lengthens. We see this relation clearly improving in the bottom two panels of Figure 2 . When we look at the fifteen-year averages, we find a strong positive relation, and an even stronger relation for the full-period averages.

The regression results confirm these observations. As the period over which we compute the averages lengthens, the slope coefficients in the regressions increase from less than 0.038 to 0.694 , and the standard errors of those regressions decrease from close to 16.6 percentage points to 10.9 percentage points. Although we can always reject the hypothesis of a unit slope, it is clear from these results that as a long-run first approximation, UIP contains a substantial kernel of truth. ${ }^{5}$

We now turn our focus of attention to the short-run deviations away from UIP.

\section{Short-run behavior and the sources of UIP deviations}

In theory, uncovered interest parity is an ex ante concept, positing equality of expected nominal returns across countries, as in equation (2):

\footnotetext{
${ }^{5}$ Lothian and Simaan (1998) provide similar evidence for a sample including many of these countries over the shorter time period,
} 


$$
i_{t}=i_{t} *+\mathrm{E}_{t}\left[\left(s_{t+1}-s_{t}\right)\right]
$$

However, empirical investigations of UIP generally use actual, ex post changes in exchange rates as a proxy for their unobservable ex ante counterparts. Therefore, deviations from UIP in can arise because of differences between actual and expected exchange rate changes and because of differences in the riskiness of the two assets:

$$
i_{t}-i_{t}^{*}-\left(s_{t+1}-s_{t}\right)=\rho_{t}+\varepsilon_{s t}
$$

where $\varepsilon_{s t}$ is the exchange rate forecast error and $\rho_{t}$ is the ex ante risk premium.

The risk premium will be positive (or negative) if investors require an expected excess return on a currency to compensate for the risk of holding it. Under the usual assumptions of rational expectations, exchange rate forecast errors will be random, given that the true underlying distribution of the exchange rate is known.

However, as Irving Fisher pointed out, there are conditions under which these errors might in fact be systematic over time. One situation in which there will be systematic errors is if investors continually anticipate changes in the underlying process generating the return distribution that have yet to occur - the "peso problem". A second situation is that of a monetary shock in the form of a sudden shift in the monetary regime. Before investors learn about the true process that generates the returns, there may be a period in which forecast errors again are systematic over time, rather than random. Fisher discussed the first of these two cases in the context of the 1896 U.S. presidential election 
and the second in the context of the stabilization of the rupee. More recently Evans and Lewis (1995) have shown in a regime-switch framework that the peso problem induces permanent shocks to the exchange rate risk premium such that it can partially explain the empirical results from the Fama regressions in Equation (1). In this paper we take another route and focus on the information contained in other international parities.

\section{A. The three-parity framework}

In order to disentangle the effects of risk premia and systematic exchange rate forecast errors on UIP, we use the framework developed in Marston (1997). We examine the deviations from UIP together with those from PPP and RIE.

We consider the expectational form of PPP in equation (4), written here in terms of expected rates of change of the variables:

$$
E_{t}\left[\pi_{t+1}-\pi_{t+1} *\right]=E_{t}\left[s_{t+1}-s_{t}\right]
$$

where $\pi_{t+1}$ and $\pi_{t+1} *$ are the rates of inflation in the home and foreign countries, respectively.

Deviations from PPP arise either as a result of exchange rate forecast errors, $\varepsilon_{s t}$, inflation forecast errors, $\varepsilon_{p t}$, or expected changes in the real exchange rate $\theta_{t}$ in Equation (5). For identification reasons we assume that PPP (in terms of rates of change) holds ex ante. ${ }^{6}$

\footnotetext{
${ }^{6}$ Dumas (1992) shows that imperfect goods arbitrage leads to a situation in which the ex ante real exchange rate can be written as a (linear) function of the ex ante real interest differential. A risk premium thus enters the PPP relation if we do not assume that PPP holds ex ante.
} 


$$
\left(\pi_{t+1}-\pi_{t+1} *\right)-\left(s_{t+1}-s_{t}\right)=\varepsilon_{s t}+\varepsilon_{p t}+\theta_{t} .
$$

When we compare equations (5) and (3), we see that risk premia do not affect deviations from PPP, but exchange rate errors affect both UIP and PPP deviations.

However, UIP, PPP, and RIE are not independent. The deviations from any one of these relations is equal to an algebraic combination of the deviations from the other two. Thus, by subtracting (5) from (3), we obtain an equation for the real-interest differential, $r-r^{*}$, in the form of equation (6):

$$
r_{t}-r_{t}^{*}=\rho_{t}-\theta_{t}-\varepsilon_{p t}
$$

When comparing (6) with (3), the risk premium is the only common component in the UIP and RIE equations. Exchange rate forecast errors do not matter for RIE.

When we compare the time paths of deviations from PPP and RIE with those from UIP we can infer the causes of the UIP deviations observed in the data. We make this comparison first in Figure 3, where we plot the deviations from the three parity conditions for the U.S. dollar-U.K. pound sterling exchange. In Table 4 we present the correlations between the deviations from the three parity conditions for the euro, the U.K. pound sterling, and the Japanese yen against the dollar. ${ }^{7}$

\section{Insert Figure 3}

\footnotetext{
${ }^{7}$ Prior to 1999 we proxy the euro by the deutschemark.
} 
What immediately strikes the eye in Figure 3 are, on the one hand, the high correlation between the UIP and PPP deviations and the similar and substantial magnitudes of both, and on the other, the low correlation between these deviations and the RIE deviations, which are very much smaller in magnitude. In Table 4 we illustrate this for all three major currencies using correlation coefficients computed for the full sample period.

\section{Insert Table 4}

Exchange rate forecast errors are common to equations (3) and (5), and explain UIP and PPP deviations. However, they do not appear in equation (6) to explain RIE deviations. In contrast, Equation (6) and Equation (3) have risk premia as a common factor. Therefore, we infer that exchange rate forecast errors rather than risk premia are the major driving force between UIP deviations.

\section{B. A dynamic factor approach to decomposing the UIP relation}

To investigate the process driving the UIP deviations, we adopt a dynamic latent factor model. Although this type of model has been extensively used in other fields, univariate models generally predominate in exchange rate studies (e.g., Wolff, 1987; and Nijman, Palm, and Wolff, 1993).

In equations (3), (5), and (6) we presented the deviations from UIP, PPP, and RIE, respectively, in terms of the risk premium, $\rho_{t}$, exchange rate forecast errors, $\varepsilon_{s t}$, inflation

forecast errors, $\varepsilon_{p t}$, and expected changes in the real exchange rate, $\theta_{t}$. Since these last 
two variables never appear separately in any of the equations, we cannot disentangle their effects. The result is a three-equation system with three common factors - the risk premia, exchange rate forecast errors, and a factor that combines inflation forecast errors and expected changes in the real exchange rate. Each of the three parity conditions is affected by just two of the factors, which makes it possible to distinguish between the effects of risk premia and exchange rate forecast errors in deviations away from the UIP relation.

Exchange rate risk premia affect only nominal and real interest differentials, not inflation differentials. Systematic errors in forecasting exchange rates affect only nominal, not real interest differentials. Thus, we have a system of three parity condition equations with three unknown factors. By estimating any combination of two parity conditions we are able to observe the ex post effects of risk premia and exchange rate forecast errors on deviations from UIP. Additionally, we can identify the ex post effects of risk premia and the combination of expected changes on the real exchange rate and inflation forecast errors on deviations from the RIE equation.

We model the set of joint parity conditions by estimating a dynamic latent factor model for UIP and RIE together. The common factor in these relations is the risk premium $\rho_{t}$.

$$
\left(\begin{array}{c}
i_{t}-i_{t}^{*}-\left(s_{t+1}-s_{t}\right) \\
r_{t}-r_{t}^{*}
\end{array}\right)=\left(\begin{array}{c}
c_{U I P} \\
c_{R I E}
\end{array}\right)+\left(\begin{array}{l}
1 \\
1
\end{array}\right) \rho_{t}+\left(\begin{array}{c}
v_{t}^{U I P} \\
v_{t}^{R I E}
\end{array}\right) .
$$

We assume the errors $v_{t}^{U I P}$ and $v_{t}^{R I E}$ to be iid with variances $\sigma_{U I P}^{2}$ and $\sigma_{R I E}^{2}$, respectively. We allow a covariance between the two errors. We consider the common 
factor for the risk premium, $\rho_{t}$, to be a latent factor, governed by an $\mathrm{AR}(1)$ process as shown in equation $(8)^{8}$,

$$
\rho_{t}=\phi_{\rho} \rho_{t-1}+\eta_{\rho t}, \quad \quad \eta_{\rho t} \sim N\left(0, \sigma_{\rho}^{2}\right) .
$$

We estimate the model parameters and the risk premium by maximum likelihood. The likelihood function is computed recursively using the Kalman filter (Harvey, 1991). Once we have estimated the common factor, the risk premium, we can identify the exchange rate forecast error $\varepsilon_{s t}$ from Equation (3) and the joint component composed of the inflation forecast error and expected real exchange rate change, $\theta_{t}+\varepsilon_{p t}$, from Equation (6).

In Table 5 we present the estimation results for the dynamic factor model for the main currencies in our sample, the euro, the British pound sterling, and the Japanese yen. ${ }^{9}$

\section{Insert Table 5}

The autoregressive coefficients on the latent lagged risk premium $\phi_{\rho}$ show that the estimated risk premium is quite persistent, with a coefficient of over 0.9 in all three cases. The standard deviations of the innovation errors are much larger for the UIP equations, $\sigma_{U I P}$, than for the RIE equations. Moreover, we find that the innovation

\footnotetext{
${ }^{8}$ Alternative specifications for the risk premium do not significantly alter the results.

${ }^{9}$ We note that our results are extremely robust to using the alternative combinations of UIP and PPP, and PPP and RIE to derive parameter estimates.
} 
variances of the risk premia $\sigma_{\rho}$ are low as well. showing that most of the variability in the deviations from UIP is caused by the expectational errors instead of being caused by variability in the risk premium.

\section{Insert Figure 4}

In Figure 4 we plot the time series of the time series of these estimates for the forecast errors and the risk premium. The latter is calculated as the smoothed estimate from the Kalman filter (see Harvey, 1991). In comparing the two, we note that in all three cases, the scales for the estimates of the risk premium are much smaller than those for the exchange rate forecast errors.

In Table 6 we compare the moments from the estimated series from the dynamic latent factor model.

\section{Insert Table 6}

We find very large positive estimates for the variances and covariances of the variables related to exchange rate expectations errors. The covariances between these errors and exchange rate changes range from 8.9 for the GBP to 10.3 for the other two currencies. The variances of the exchange rates have similar magnitudes. Although the covariance of the risk premia with the exchange rate is negative, the empirical estimates for all three currencies are small in value with the highest value being -0.1 for the sterling.

The variance of the risk premium is between 0.022 and 0.067 for the three currencies, whereas strikingly, the variance of the exchange rate and the associated 
forecast errors are around 10. Froot and Frankel (1989) find estimates similar in magnitude in their survey data. Importantly, these results show that the variability of the risk premium is much lower than the variability of expected exchange rate returns. As a result the rejection of UIP cannot be attributed completely to the existence of a risk premium. Exchange rate forecast errors appear to play a much more important role in terms of variability than risk premia.

\section{Expectational Errors and the UIP puzzle}

The question that we now address concerns the determination of the relative size of the impacts of the risk premium and the exchange rate forecast error on the estimate of the beta in the original UIP regression (1). To answer this question we decompose the estimate of the slope coefficient in this regression. We first write the estimated slope coefficient for the UIP regression in terms of the standard OLS formula:

$$
\beta_{O L S}=\frac{\operatorname{cov}\left(i_{t}-i_{t}^{*}, s_{t+1}-S_{t}\right)}{\operatorname{var}\left(i_{t}-i_{t}^{*}\right)} .
$$

A wide body of empirical evidence shows that these beta estimates are generally negative. From Equation (9) we see that a negative slope coefficient can only occur if the covariance between the interest differential and the exchange rate change is negative.

To determine the specific effects of the risk premia and exchange rate errors on the regression coefficient, we follow Engel (1996), who decomposes the beta into a beta related to the risk premium, $\beta_{r p}$, and a beta for the expectational errors, $\beta_{s s}$. In our case 
we rewrite the numerator from Equation (9) using the decomposition in Equation (3). More specifically, we find that

$$
\operatorname{cov}\left(i_{t}-i_{t}^{*}, s_{t+1}-s_{t}\right)=\operatorname{var}\left(i_{t}-i_{t}{ }^{*}\right)-\operatorname{cov}\left(\rho_{t}, i_{t}-i_{t}^{*}\right)-\operatorname{cov}\left(\varepsilon_{s t}, i_{t}-i_{t}^{*}\right)
$$

This decomposition allows us to write the OLS beta as

$$
\beta_{O L S}=1-\beta_{r p}-\beta_{s s},
$$

with the beta for the risk premium $\beta_{r p}$ defined by

(12) $\beta_{r p}=\frac{\operatorname{cov}\left(\rho_{t}, i_{t}-i_{t}^{*}\right)}{\operatorname{var}\left(i_{t}-i_{t}^{*}\right)}$,

and the beta for the expectational errors as,

$$
\beta_{s s}=\frac{\operatorname{cov}\left(\varepsilon_{s t}, i_{t}-i_{t}^{*}\right)}{\operatorname{var}\left(i_{t}-i_{t}^{*}\right)}
$$

When we replace the moments in (12) and (13) with their sample equivalents, we find that the beta for the expectational error, $\beta_{s s}$, is larger than the beta for the risk premium, $\beta_{r p}$ for all three exchange rates. In Table 6 we report these results. 
The values for $\beta_{r p}$ range from 0.368 (EUR) to 0.521 (JPY), whereas the values for $\beta_{s s}$ range from 1.816 (EUR) to 3.624 (JPY). For all currencies the values for $\beta_{s s}$ are much larger than the values for $\beta_{r p}$. As a result the decomposition of the OLS regression coefficient from Equation (11) provides compelling evidence that it is the exchange rate forecast errors and not the risk premium that is mainly responsible for the negative regression coefficients in the UIP regressions (1).

Irving Fisher related the failure of UIP to a failure by investors to adjust accurately and promptly to changes in prices, but only with a long lag. Interestingly, Bacchetta and van Wincoop (2007) stress a similar line of thought when they introduce a model where agents make infrequent decisions when trading foreign exchange due to e.g. management fees. Bacchetta and van Wincoop (2007) find that this phenomenon could explain the negative coefficients in the Fama regression.

Engel, Mark and West (2007) build on the observation that short-run movements in exchange rates are primarily determined by changes in expectations. They show that the empirical behavior of exchange rates is consistent with models based on economic fundamentals, when exchange rates are viewed as asset prices that react to economic news. As a result exchange rate models, like UIP, can be perfectly consistent with economic theory, although they may not predict exchange rates that well out of sample. Engel, Mark and West (2007) stress that more efforts should be put into understanding why exchange rate market participants make forecast errors.

In summary, our empirical results provide additional support for Fisher's proposition that the negative slope coefficients that are often obtained in UIP regressions 
depend mainly on errors in exchange rate expectations and not on time variation in the risk premium.

\section{Conclusion}

Our results for UIP are consistent with those reported a century and more ago by Irving Fisher in his studies of the relation between appreciation and interest, both in its UIP and interest vs. inflation versions. Consistent with Fisher's view, we find evidence of the important role played by episodic phenomena in disturbing that relation. Like Fisher, we too find that the influence of such phenomena dissipates over time.

We conclude that there are long-run deviations from parity conditions that appear to be caused by large, but infrequent, shocks to the monetary environment. These shocks systematically affect the error in forecasting the change in exchange rates. Over the long term, these errors are less important and we find empirical support for UIP.

Using Marston's (1997) analysis, we investigate the possibility of a common factor driving short-run deviations from international parity conditions. We find extremely high correlation coefficients between UIP and PPP deviations that we identify with exchange rate forecasting errors.

Using a dynamic latent variable model, we estimate the risk premium and exchange rate forecast error parameters that drive changes in deviations from UIP. We find evidence of large and persistent forecasting errors. Although we can hypothesize about what may be driving the persistent errors in forecasting exchange rates, we do not attempt to model predictability in excess returns. Instead, using a latent factor model, we 
provide strong empirical support that it is indeed expectational errors rather than the risk premium that underlie the short-run deviations from UIP.

Our results are in line with the survey literature, e.g. Froot and Frankel (1989), on exchange rate expectations, which decomposes expectations in a risk premium component and exchange rate forecast errors. The common finding there is that the risk premium plays a limited role, and most variation is due to the expectational errors.

Our results strengthen the case for further research in the way expectations are formed. Note that Irving Fisher was a pioneer in this field as well, as he already anticipated the development of adaptive expectations in his 1911 study The Purchasing Power of Money (see also Dimand and Geanakoplos, 2005) and applied that methodology econometrically to the study of interest rates (Fisher, 1930). Interestingly, in a recent study Mark (2005) stresses the importance of exchange rate expectations and, in particular, the role of learning about monetary policy rules. In our opinion, applying the recent research on the formation of expectations and learning may be a promising approach in increasing our understanding of exchange rate behavior. 


\section{References}

Bacchetta, Philippe, and Eric van Wincoop. 2007. "Random Walk Expectations and the Forward Discount Puzzle." American Economic Review, 97: 346-350.

Backus, David, Silverio Foresi, Abon Mozumdar and Liuren Wu, 2001. Predictable changes in yields and forward rates. Journal of Financial Economics 59, 281-311.

Bekaert, Geert, Hodrick, Robert J., 2001. Expectation hypotheses tests. Journal of Finance 56, 1357-1394.

Bekaert, Geert, Min Wei and Yuhang Xing., 2003. Uncovered interest rate parity and the term structure. manuscript. Columbia University.

Brennan, Michael J. and Yihong Xia, 2005. International capital markets and foreign exchange risk. Unpublished working paper, UCLA and University of Pennsylvania.

Chinn, Menzie D., 2006. The (partial) rehabilitation of interest rate parity in the floating rate era: Longer horizons, alternative expectations, and emerging markets. Journal of International Money and Finance, 25, 7-21. 
Dimand, Robert. 1999. "Irving Fisher and the Fisher Relation: Setting the Record Straight." Canadian Journal of Economics / Revue canadienne d'Economique, 32: 744750.

Dimand, Robert, and John Geanakoplos. 2005. "Celebrating Irving Fisher: The legacy of a great economist." American Journal of Economics and Sociology, 64: 3-18.

Dumas, Bernard. 1992. "Dynamic Equilibrium and the Real Exchange Rate in a Spatially Separated World.” Review of Financial Studies, 5: 153-180.

Engel, Charles. 1996. "The forward discount anomaly and the risk premium: A survey of recent evidence.” Journal of Empirical Finance 3: 123-191.

Engel, Charles, Nelson C. Mark and Kenneth D. West. 2007, "Exchange rate models are not as bad as you think." Unpublished working paper, University of Wisconsin.

Evans, Martin and Karen Lewis. 1995. "Do long-term swings in the dollar affect estimates of the risk premia?" Review of Financial Studies, 8: 709-742.

Fama, Eugene F. 1984. "Forward and spot exchange rates." Journal of Monetary Economics 14: 319-338.

Fisher, Irving. 1896. Appreciation and Interest. New York: Macmillan. 
Fisher, Irving., 1907. The Rate of Interest. New York: Macmillan.

Fisher, Irving. 1911. ThePurchasing Power of Money, 1911, New York: Macmillan.

Fisher, Irving. 1930. The Theory of Interest. New York: MacMillan.

Flood, Robert and Andrew Rose, 2002. "Uncovered interest parity in crisis: The interest rate defense in the 1990s," IMF. Staff Papers, 49: 252-266.

Friedman, Milton and Anna J. Schwartz. 1991 "Alternative Approaches to Analyzing Economic Data," American Economic Review,. 81: 39-49.

Froot, Kenneth A. and Jeffrey A. Frankel. 1989. "Forward Discount Bias: Is it an Exchange Risk Premium?" Quarterly Journal of Economics, 104: 139-161.

Hallwood, C. Paul, Ronald MacDonald and Ian W. Marsh, 2000. Realignment expectations and the U.S. dollar, 1890-1897: Was there a 'peso problem'?. Journal of Monetary Economics 46, 605-620.

Harvey, Andrew A., 1991, Forecasting, Structural Time Series Models and the Kalman Filter. Cambridge: Cambridge University Press. 
Hodrick, Robert, 1987. The Empirical Evidence on the Efficiency of Forward and Futures Foreign Exchange Markets, New York: Harwood Academic Publishers.

Lothian, James R. and Yusif Simaan, 1998. International financial relations under the current float: Evidence from panel data. Open Economies Review 9: 293-313.

Lothian, James R. and Liuren Wu, 2005, "Uncovered Interest Rate Parity over the Past Two Centuries." Unpublished working paper, Fordham University and Baruch College.

Lucas, Robert E., Jr. 1980, "Two Illustrations of the Quantity Theory of Money," American Economic Review,. 70: 1005-1004.

Mark, Nelson C. 2005. "Changing monetary policy rules, learning, and real exchange rate dynamics.” Unpublished working paper, University of Notre Dame.

Marston, Richard. 1997. "Tests of three parity conditions: Distinguishing risk premia and systematic forecast errors." Journal of International Money and Finance 16: 285303.

Nijman, Theo, Franz Palm, and Christian Wolff. 1993, "Premia in Forward Foreign Exchange as Unobserved Components: A Note." Journal of Business and Economic Statistics, 11: 361-365. 
Wolff, Christian. 1987, "Forward Foreign Exchange Rates, Expected Spot Rates, and Premia: A Signal-Extraction Approach.” Journal of Finance, 41: 395-406. 


\section{Table 1: Summary of results of individual-country UIP regressions}

We run the regressions summarized below by using monthly data from 1976:1-2005:12 obtained from International Financial Statistics. These regressions take the form

$$
s_{t+1}-s_{t}=\alpha+\beta\left(i_{t}-i_{t} *\right)+e_{t+1}, \quad \text { (Eq. 1) }
$$

where $s_{t+1}-s_{t}$ is the one-period change in the log of the spot foreign exchange rate measured as the foreign currency price of the U.S. dollar. The corresponding interest rate differential $i_{t}-i_{t} *$ is measured as the foreign minus the U.S. interest rate. We note that for some countries interest-rate data are only available at a later starting date.

\begin{tabular}{lrrrrrrrr}
\hline Full Sample & & Standard & t-Stat & \multicolumn{7}{c}{ Standard } & t- Stat & \\
Regression & $\alpha$ & Error & $\alpha=\mathbf{0}$ & $\beta$ & Error & $\beta=\mathbf{1}$ & $\boldsymbol{R}^{2}$ & $\mathbf{N}$ \\
\hline Austria & -2.700 & 2.187 & -1.235 & -1.016 & 0.739 & -2.728 & 0.005 & 360 \\
Australia & 3.746 & 2.441 & 1.535 & -0.721 & 0.575 & -2.993 & 0.004 & 360 \\
Belgium & 1.182 & 2.260 & 0.523 & -1.543 & 0.901 & -2.823 & 0.008 & 360 \\
Canada & 1.920 & 1.389 & 1.382 & -0.891 & 0.585 & -3.231 & 0.006 & 360 \\
Denmark & 1.007 & 2.475 & 0.407 & -0.338 & 0.537 & -2.490 & 0.001 & 360 \\
Finland & 1.418 & 2.167 & 0.654 & -0.615 & 0.925 & -1.746 & 0.001 & 312 \\
France & 1.732 & 2.461 & 0.704 & -0.739 & 0.831 & -2.092 & 0.002 & 346 \\
Germany & -0.233 & 0.188 & -1.238 & -1.191 & 0.861 & -2.545 & 0.005 & 354 \\
Greece & -1.598 & 4.159 & -0.384 & 0.146 & 0.386 & -2.212 & 0.001 & 240 \\
Ireland & 0.660 & 2.397 & 0.275 & 0.134 & 0.460 & -1.881 & 0.000 & 360 \\
Italy & -0.237 & 3.257 & -0.073 & 0.740 & 0.611 & -0.426 & 0.005 & 312 \\
Japan & -0.865 & 0.242 & -3.574 & -3.157 & 0.861 & -4.827 & 0.036 & 360 \\
Netherlands & -0.557 & 2.199 & -0.253 & -2.014 & 0.924 & -3.263 & 0.015 & 312 \\
New Zealand & 2.040 & 2.005 & 1.017 & -0.749 & 0.245 & -7.138 & 0.025 & 360 \\
Norway & 1.296 & 2.385 & 0.543 & -0.224 & 0.523 & -2.341 & 0.001 & 360 \\
Portugal & -0.318 & 2.686 & -0.118 & 0.228 & 0.429 & -1.798 & 0.001 & 240 \\
Spain & 4.462 & 0.487 & 9.171 & 0.424 & 0.102 & -5.673 & 0.053 & 312 \\
Sweden & 1.847 & 2.340 & 0.789 & 0.064 & 0.608 & -1.539 & 0.000 & 360 \\
Switzerland & -6.173 & 2.966 & -2.081 & -1.189 & 0.605 & -3.616 & 0.011 & 360 \\
UK & 0.492 & 0.236 & 2.087 & -2.182 & 0.847 & -3.757 & 0.018 & 360 \\
\hline & & & & & & & &
\end{tabular}


Table 2: Results of UIP regressions based on Irving Fisher's (1930) data for U.S. gold and greenback bonds and Indian sterling and rupee bonds

In the regressions summarized below we use the data reported in Tables 11 and 12 of Fisher's The Theory of Interest (1930). These regressions take the form

$$
s_{t+1}-s_{t}=\alpha+\beta\left(i_{t}-i_{t}^{*}\right)+e_{t+1}, \quad \text { (Eq. 1) }
$$

where $s_{t+1}-s_{t}$ is the one-period change in the log of the spot foreign exchange rate measured as the foreign currency price of the U.S. dollar. The corresponding interest rate differential $i_{t}-i_{t} *$ is measured as the foreign minus the U.S. interest rate.

\begin{tabular}{lrrrrrrr}
\hline & & Standard & t-Stat & & Standard & t- Stat & \\
Average & $\alpha$ & Error & $\alpha=\mathbf{0}$ & $\beta$ & Error & $\beta=1$ & $\mathbf{R}^{2}$ \\
\hline U.S. Bonds & -1.037 & 0.724 & -1.433 & 2.608 & 1.434 & 1.122 & 0.091 \\
Indian Bonds & -0.020 & 1.369 & -0.014 & -2.012 & 2.435 & -1.237 & 0.019 \\
\hline
\end{tabular}




\section{Table 3: Results of UIP regressions for nonoverlapping averages of the data}

The regressions we summarize below are pooled regressions that we run using the averaged data. These regressions take the form

$$
s_{t+1}-s_{t}=\alpha+\beta\left(i_{t}-i_{t} *\right)+e_{t+1}, \quad \text { (Eq. 1) }
$$

where $s_{t+1}-s_{t}$ is the one-period change in the log of the spot foreign exchange rate measured as the foreign currency price of the U.S. dollar. The corresponding interest rate differential $i_{t}-i_{t} *$ is measured as the foreign minus the U.S. interest rate.

Observations are missing for some countries, since some series have later starting dates. The countries we analyze are Austria, Australia, Belgium, Canada, Denmark, Finland, France, Germany, Greece, Ireland, Italy, Japan, the Netherlands, New-Zealand, Norway, Portugal, Spain, Sweden, Switzerland, and the UK.

\begin{tabular}{|c|c|c|c|c|c|c|c|c|c|}
\hline Average & Intercept & $\begin{array}{l}\text { Standard } \\
\text { Error }\end{array}$ & $\begin{array}{l}\text { t-Stat } \\
\alpha=0\end{array}$ & Beta & $\begin{array}{l}\text { Standard } \\
\text { Error }\end{array}$ & $\begin{array}{l}\text { t-Stat } \\
\beta=1\end{array}$ & $\mathbf{R}^{2}$ & $S E E$ & Nobs \\
\hline 5-year & 0.233 & 0.651 & 0.359 & 0.038 & 0.166 & -5.783 & 0.001 & 6.044 & 106 \\
\hline 15-year & -0.577 & 0.306 & -1.886 & 0.694 & 0.109 & -2.808 & 0.583 & 1.494 & 31 \\
\hline 30-year & -0.481 & 0.433 & -1.111 & 0.583 & 0.166 & -2.516 & 0.421 & 1.583 & 19 \\
\hline
\end{tabular}


Table 4: Correlation of deviations from ex-post UIP, PPP, and RIE

The currencies we use are the euro (EUR), British pound sterling (GBP), and Japanese yen (JPY), all measured as the foreign currency price of the U.S. dollar. The estimation period is from January 1976 to December 2005.

\begin{tabular}{llll}
\hline Full sample & UIP \& PPP & UIP \& RIE & PPP \& RIE \\
\hline & & & \\
Euro & 0.994 & 0.034 & 0.11 \\
Japan & 0.981 & 0.030 & 0.171 \\
UK & 0.981 & -0.020 & 0.153 \\
\hline
\end{tabular}


Table 5: Estimation results for the dynamic factor model (7) and (8)

This table presents parameter estimates for the dynamic factor model consisting of equations:

$\left(\begin{array}{c}i_{t}-i_{t} *-\left(s_{t+1}-s_{t}\right) \\ r_{t}-r_{t}^{*}\end{array}\right)=\left(\begin{array}{c}c_{U I P} \\ c_{R I E}\end{array}\right)+\left(\begin{array}{l}1 \\ 1\end{array}\right) \rho_{t}+\left(\begin{array}{c}v_{t}^{U I P} \\ v_{t}^{R I E}\end{array}\right)$

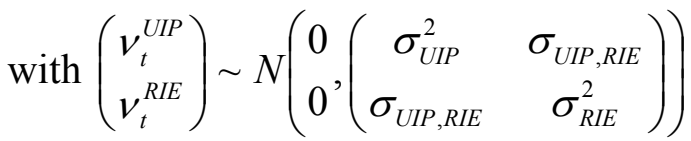

The risk premium, $\rho_{t}$, is modeled as:

$\rho_{t}=\phi_{\rho} \rho_{t-1}+\eta_{\rho t}, \quad \eta_{\rho t} \sim N\left(0, \sigma_{\rho}^{2}\right) \quad$ (Eq. 8)

The currencies we use are the euro (EUR), British pound sterling (GBP), and Japanese yen (JPY), all measured as the foreign currency price of the U.S. dollar. The estimation period is from January 1976 to December 2005. Standard errors are provided within parentheses.

\begin{tabular}{|c|c|c|c|}
\hline & EUR & GBP & JPY \\
\hline$c_{U I P}$ & $0.196 \quad(0.034)$ & $-0.046 \quad(0.002)$ & $0.073 \quad(0.131)$ \\
\hline$c_{R I E}$ & $0.050 \quad(0.046)$ & $0.071 \quad(0.001)$ & $0.004 \quad(0.041)$ \\
\hline$\phi_{\rho}$ & $0.943 \quad(0.018)$ & $0.927 \quad(0.001)$ & $0.919 \quad(0.014)$ \\
\hline$\sigma_{\rho}$ & $0.049 \quad(0.003)$ & $0.070 \quad(0.000)$ & $0.075 \quad(0.003)$ \\
\hline$\sigma_{U I P}$ & $3.211 \quad(0.000)$ & $3.951 \quad(0.000)$ & $3.098 \quad(0.000)$ \\
\hline$\sigma_{R I E}$ & $0.032 \quad(0.000)$ & $0.015 \quad(0.000)$ & $0.013 \quad(0.000)$ \\
\hline$\sigma_{U I P, R I E}$ & $0.017 \quad(0.000)$ & $0.003 \quad(0.000)$ & $0.002 \quad(0.000)$ \\
\hline
\end{tabular}




\section{Table 6: Moments}

The currencies we use are the euro (EUR), British pound sterling (GBP), and Japanese yen (JPY), all measured as the foreign currency price of the U.S. dollar. The estimation period is from January 1976 to December 2005. We calculate $\beta_{O L S}, \beta_{r p}$, and $\beta_{s s}$ as

$$
\frac{\operatorname{cov}\left(i_{t}-i_{t}^{*}, s_{t+1}-s_{t}\right)}{\operatorname{var}\left(i_{t}-i_{t}^{*}\right)}, \frac{\operatorname{cov}\left(\rho_{t}, i_{t}-i_{t}^{*}\right)}{\operatorname{var}\left(i_{t}-i_{t}^{*}\right)} \text {, and } \frac{\operatorname{cov}\left(\varepsilon_{s t}, i_{t}-i_{t}^{*}\right)}{\operatorname{var}\left(i_{t}-i_{t} *\right)} \text {, respectively. Note }
$$

that $\beta_{O L S}=1-\beta_{r p}-\beta_{s s}$.

\begin{tabular}{|l|r|r|r|}
\hline & EUR & GBP & JPY \\
\hline $\operatorname{var}\left(s_{t+1}-s_{t}\right)$ & 10.366 & 9.352 & 11.802 \\
$\operatorname{var}\left(i_{t}-i_{t}^{*}\right)$ & 0.039 & 0.036 & 0.043 \\
$\operatorname{cov}\left(i_{t}-i_{t}^{*}, s_{t+1}-s_{t}\right)$ & -0.047 & -0.078 & -0.135 \\
$\operatorname{var}\left(\rho_{t}\right)$ & 0.021 & 0.047 & 0.036 \\
$\operatorname{var}\left(\varepsilon_{s t}\right)$ & 10.471 & 9.407 & 11.966 \\
$\operatorname{cov}\left(\rho_{t}, i_{t}-i_{t}^{*}\right)$ & 0.015 & 0.015 & 0.022 \\
$\operatorname{cov}\left(\varepsilon_{s t}, i_{t}-i_{t}^{*}\right)$ & 0.072 & 0.098 & 0.155 \\
$\beta_{O L S}$ & -1.187 & -2.176 & -3.148 \\
$\beta_{r p}$ & 0.368 & 0.432 & 0.521 \\
$\beta_{s s}$ & 1.816 & 2.741 & 3.624 \\
\hline
\end{tabular}


Figure 1: Averages of coefficients from five-year rolling regressions for the G7 countries and one-standard-deviation bounds

We report the beta estimates from the 5 year rolling regression summarized below by using monthly data from January 1976- December 2005 obtained from International Financial Statistics. These regressions take the form

$$
s_{t+1}-s_{t}=\alpha+\beta\left(i_{t}-i_{t}^{*}\right)+e_{t+1}
$$

where $s_{t+1}-s_{t}$ is the one-period change in the log of the spot foreign exchange rate measured as the foreign currency price of the U.S. dollar. The corresponding interest rate differential $i_{t}-i_{t} *$ is measured as the foreign minus the U.S. interest rate. We note that for some countries interest-rate data are only available at a later starting date. We take the G7 countries.

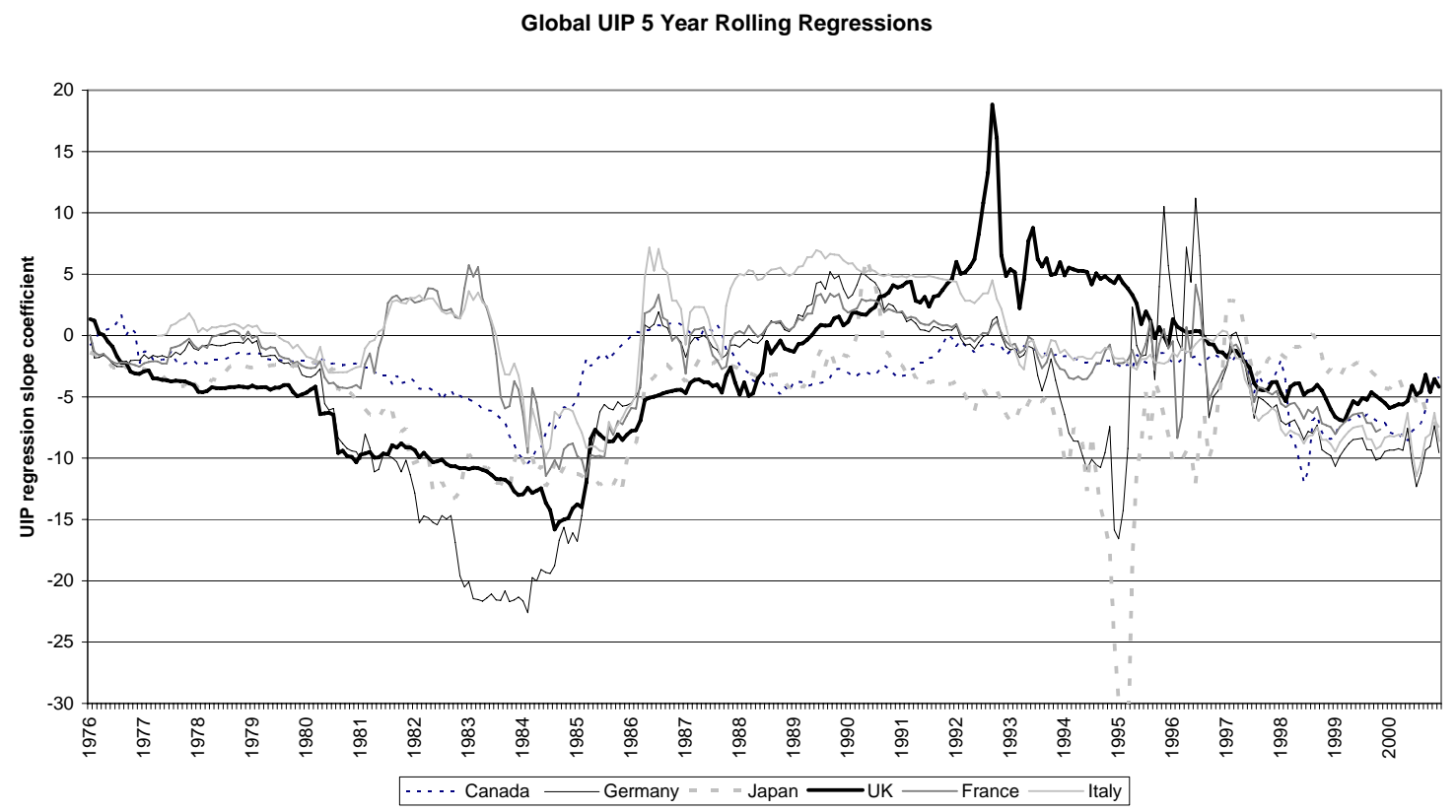




\section{Figure 2: UIP relations based on five-year, 15-year and full-period averages}

In the charts below we plot period averages of the exchange rate change against the interest differential for all 18 countries. For Spain and Portugal these data begin in 1985. The 5-year sample periods were January 1976- December 1980, January 1981- December 1985, January 1986- December 1990, January 1991-1995, January 1996- December 2000, January 2001- December 2005; the 15 year sample periods were January 1976December 1990 and January 1991- December 2005.

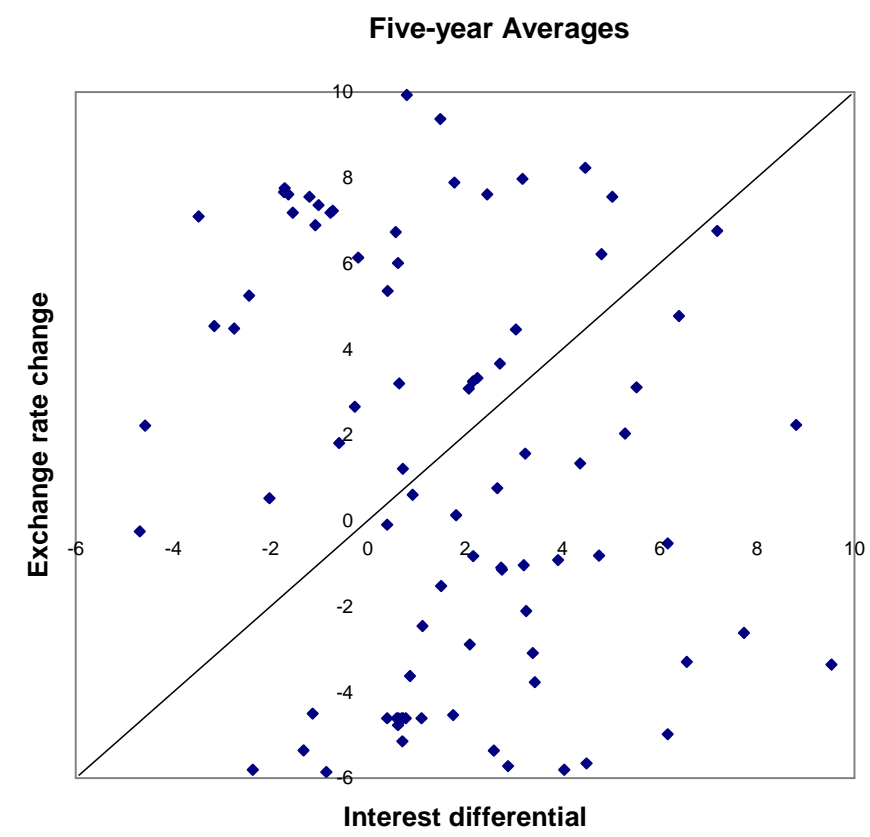


Fifteen-year Averages
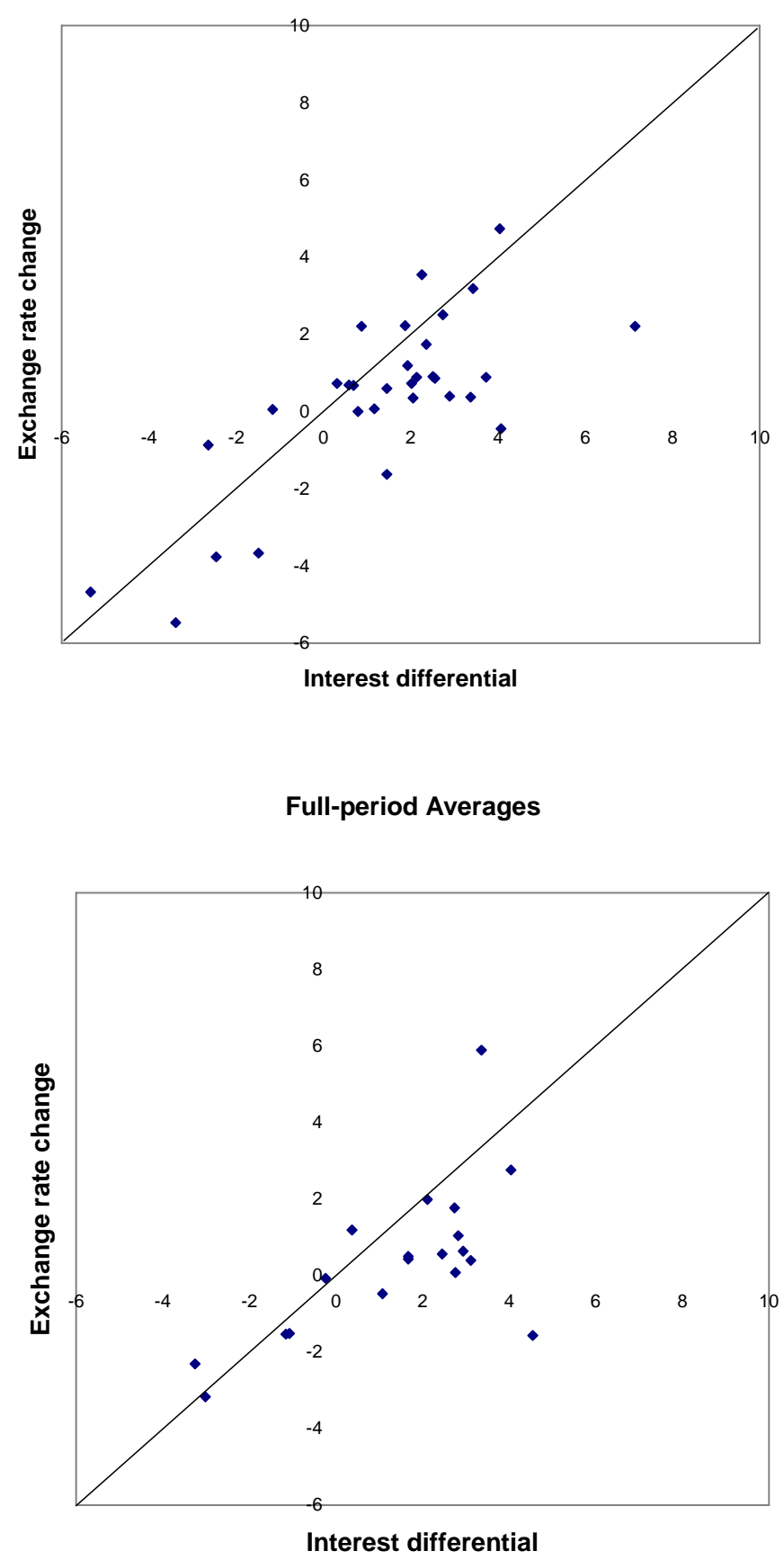
Figure 3: Ex post deviations from UIP, PPP, and RIE for the US and the UK from January 1976 - December 2005.

We plot ex post deviations from the three equations:

$$
\begin{aligned}
& i_{t}-i_{t} *-\left(s_{t+1}-s_{t}\right)=\rho_{t}-\varepsilon_{s t}, \\
& E_{t}\left[\pi_{t+1}-\pi_{t+1} *\right]-E_{t}\left[s_{t+1}-s_{t}\right]=\varepsilon_{s t}+\varepsilon_{p t}+\theta_{t} \\
& r_{t}-r_{t}^{*}=\rho_{t}-\theta_{t}-\varepsilon_{p t}, \quad \text { (Eq. 6) }
\end{aligned}
$$

where $s_{t+1}-s_{t}$ is the one-period change in the log of the spot foreign exchange rate measured as the foreign currency price of the U.S. dollar. The corresponding interest rate differential $i_{t}-i_{t} *$ is measured as the foreign minus the U.S. interest rate. $\pi$ and $\pi^{*}$ are the rates of inflation in the foreign country and the U.S. $r-r^{*}$ is the real-interest differential. $\rho_{t}$, is the risk premia, $\varepsilon_{s t}$, is the exchange rate forecast error, $\varepsilon_{p t}$, is the inflation forecast error, and $\theta_{t}$ : is the expected changes in the real exchange rate.

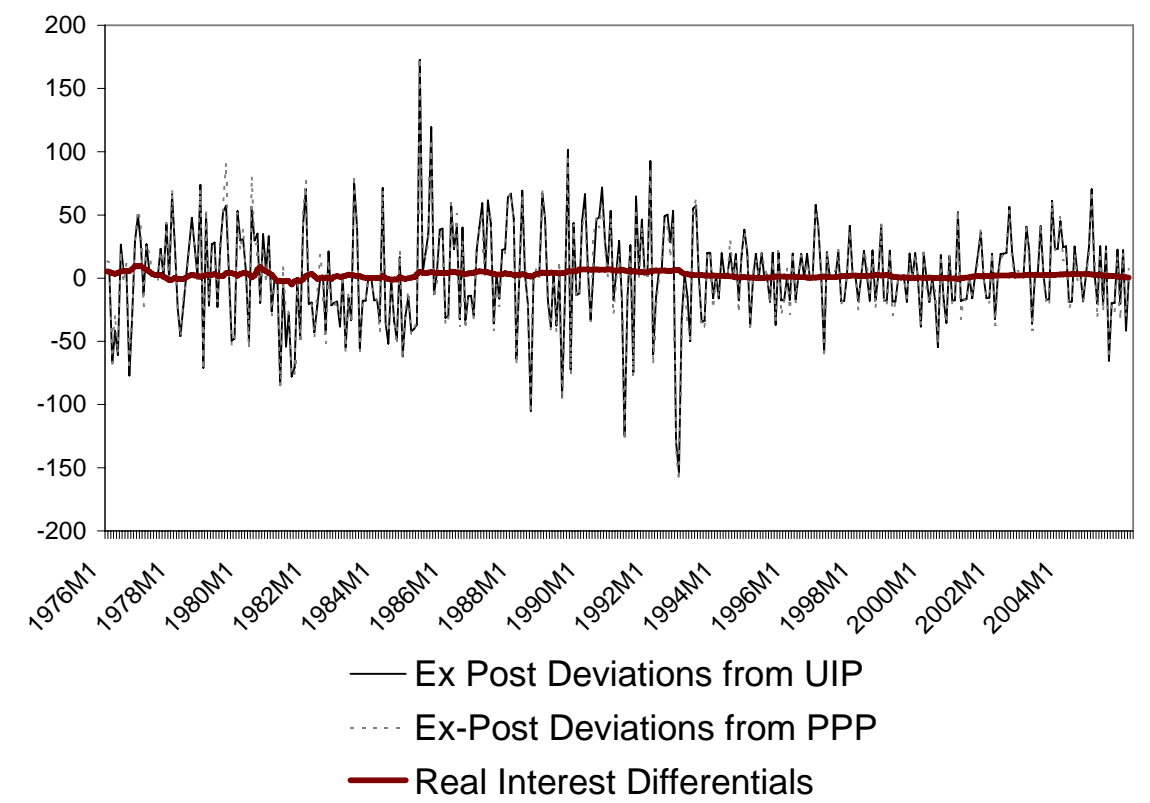


Figure 4: Estimated factors from the dynamic factor model

The table plots the parameter estimates from the dynamic factor model consisting of equations:

$$
\left(\begin{array}{c}
i_{t}-i_{t} *-\left(s_{t+1}-s_{t}\right) \\
r_{t}-r_{t}^{*}
\end{array}\right)=\left(\begin{array}{l}
c_{U I P} \\
c_{R I E}
\end{array}\right)+\left(\begin{array}{l}
1 \\
1
\end{array}\right) \rho_{t}+\left(\begin{array}{l}
v_{t}^{U I P} \\
v_{t}^{R I E}
\end{array}\right)
$$

Where the risk premium, $\rho_{t}$, is modeled as:

$$
\left.\rho_{t}=\phi_{\rho} \rho_{t-1}+\eta_{\rho t}, \quad \eta_{\rho t} \sim N\left(0, \sigma_{\rho}^{2}\right) \quad \text { (Eq. } 8\right)
$$

The currencies we use are the euro (EUR), British pound sterling (GBP), and Japanese yen (JPY), all measured as the foreign currency price of the U.S. dollar. The estimation period is from January 1976 to December 2005.

\section{Euro}

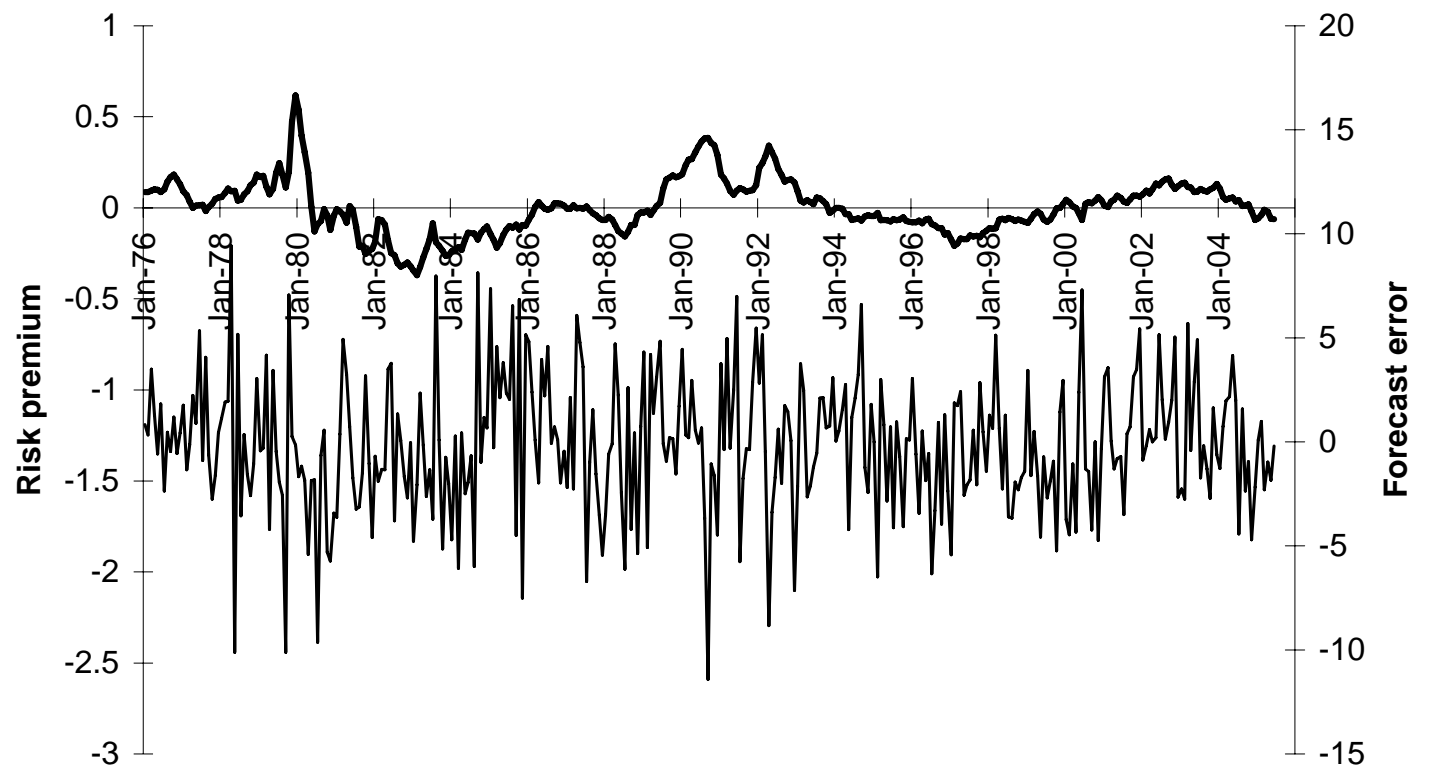

Risk premium — Forecast error 
GBP:

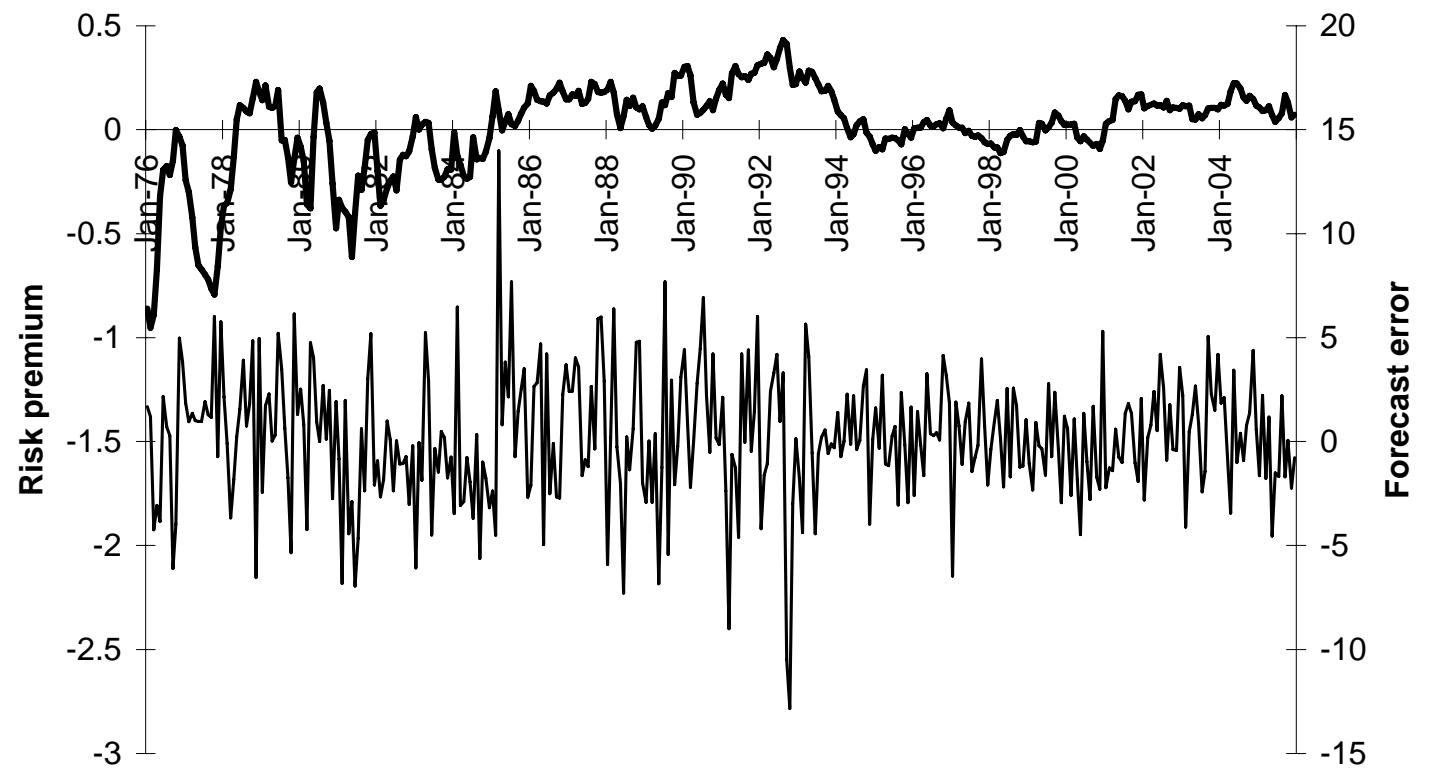

JPY:

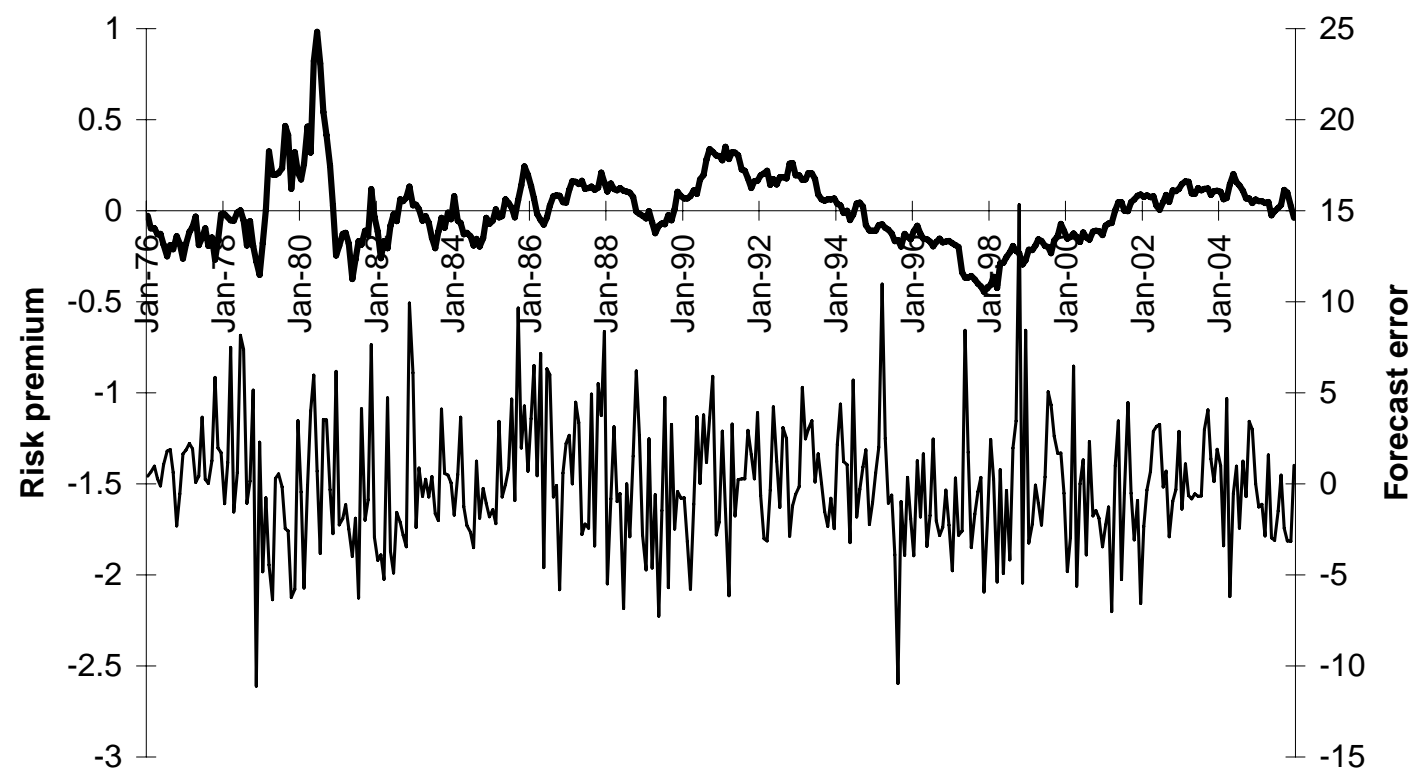

Risk premium — Forecast error 


\section{Publications in the Report Series Research ${ }^{*}$ in Management}

\section{ERIM Research Program: "Finance and Accounting"}

2007

Revisiting Uncovered Interest Rate Parity: Switching Between UIP and the Random Walk

Ronald Huisman and Ronald Mahieu

ERS-2007-001-F\&A

http://hdl.handle.net/1765/8288

Hourly Electricity Prices in Day-Ahead Markets

Ronald Huisman, Christian Huurman and Ronald Mahieu

ERS-2007-002-F\&A

http://hdl.handle.net/1765/8289

Do Exchange Rates Move in Line with Uncovered Interest Parity?

Ronald Huisman, Ronald Mahieu and Arjen Mulder

ERS-2007-012-F\&A

http://hdl.handle.net/1765/8993

Hedging Exposure to Electricity Price Risk in a Value at Risk Framework

Ronald Huisman, Ronald Mahieu and Felix Schlichter

ERS-2007-013-F\&A

http://hdl.handle.net/1765/8995

Corporate Governance and Acquisitions: Acquirer Wealth Effects in the Netherlands

Abe de Jong, Marieke van der Poel and Michiel Wolfswinkel

ERS-2007-016-F\&A

$\underline{\text { http://hdl.handle.net/1765/9403 }}$

The Effect of Monetary Policy on Exchange Rates during Currency Crises; The Role of Debt, Institutions and Financial Openness

Sylvester C.W. Eijffinger and Benedikt Goderis

ERS-2007-022-F\&A

http://hdl.handle.net/1765/9725

Do Private Equity Investors Take Firms Private for Different Reasons?

Jana P. Fidrmuc, Peter Roosenboom and Dick van Dijk

ERS-2007-028-F\&A

http://hdl.handle.net/1765/10070

The Influence of Temperature on Spike Probability in Day-Ahead Power Prices

Ronald Huisman

ERS-2007-039-F\&A

http://hdl.handle.net/1765/10179

Costs and Recovery Rates in the Dutch Liquidation-Based Bankruptcy System

Oscar Couwenberg and Abe de Jong

ERS-2007-041-F\&A

http://hdl.handle.net/1765/10461

The Volatility Effect: Lower Risk without Lower Return

David C. Blitz and Pim van Vliet

ERS-2007-044-F\&A

http://hdl.handle.net/1765/10460 
Strategic Debt: Evidence from Bertrand and Cournot Competition

Abe de Jong, Thuy Thu Nguyen and Mathijs A. van Dijk

ERS-2007-057-F\&A

http://hdl.handle.net/1765/10504

Capital Structure Around the World: The Roles of Firm- and Country-Specific Determinants

Abe de Jong, Rezaul Kabir and Thuy Thu Nguyen

ERS-2007-058-F\&A

http://hdl.handle.net/1765/10517

The Effects of Federal Funds Target Rate Changes on S\&P100 Stock Returns, Volatilities, and Correlations Helena Chulia-Soler, Martin Martens and Dick van Dijk ERS-2007-066-F\&A

http://hdl.handle.net/1765/10610

Industry Valuation Driven Earnings Management

Tao Jiao, Gerard Mertens and Peter Roosenboom

ERS-2007-069-F\&A

http://hdl.handle.net/1765/10608

The Impact of Media Attention on the Use of Alternative Earnings Measures

Miriam Koning, Gerard Mertens and Peter Roosenboom

ERS-2007-073-F\&A

http://hdl.handle.net/1765/10609

Irving Fisher and the UIP Puzzle: Meeting the Expectations a Century Later

Rachel A. Campbell, Kees G. Koedijk, James R. Lothian and Ronald J. Mahieu

ERS-2007-088-F\&A

http://hdl.handle.net/1765/10774

Electricity Portfolio Management: Optimal Peak / Off-Peak Allocations

Ronald Huisman, Ronald J. Mahieu and Felix Schlichter

ERS-2007-089-F\&A

http://hdl.handle.net/1765/10775

* A complete overview of the ERIM Report Series Research in Management: https://ep.eur.nl/handle/1765/1

ERIM Research Programs:

LIS Business Processes, Logistics and Information Systems

ORG Organizing for Performance

MKT Marketing

F\&A Finance and Accounting

STR Strategy and Entrepreneurship 